REVISTA DE DERECHO UNED, núm. 6, 2010

\title{
UNA APROXIMACIÓN AL CONCEPTO PROCESAL DE «ACCIÓN»*
}

\author{
SONIA CALAZa LÓPEZ \\ Profesora Titular acreditada de Derecho Procesal de la UNED
}

Resumen: Este trabajo aborda, de manera sintética, la evolución del concepto de "acción», conforme a las Teorías concreta, abstracta y ecléctica, para concluir con un ensayo original de dicho concepto de «acción».

Palabras clave: Acción, Teorías concreta, abstracta y ecléctica.

Abstract: This work raises, in a synthetic way, the evolution of the concept of "action», in accordance with the concrete, abstract and eclectic Theories, and concludes with an original essay of the above mentioned concept of «action».

Keywords: Action, Concrete, abstract and eclectic Theories.

Sumario: I. Concepto y fundamento.-1. Teoría concreta.-A. Gómez Orbaneja.-B. De la Oliva.-C. Ensayo del concepto «acción».-D. Manifestaciones de la Teoría concreta en la LEC 1/2000.-2. Teoría abstracta.-A. Guasp.-B. Fairén.-C. Prieto-Castro.-D. Montero Aroca.-E. Alcalá-Zamora.-F. Gimeno.-3. Teoría ecléctica.-4. A modo de conclusión sobre la acción y la defensa. La pretensión. Apuntes para un concepto.-II. Bibliografía.

* Este trabajo ha sido realizado en el marco del Proyecto de Investigación del Ministerio de Ciencia e Innovación, con referencia SEJ 2007-62039, del que es investigador principal el Prof. Vicente Gimeno Sendra (Catedrático de la Universidad Nacional de Educación a Distancia). 


\section{CONCEPTO Y FUNDAMENTO}

La primera concepción de la acción vino determinada, en sus orígenes, por su indisoluble unión al derecho material, de tal suerte que para la doctrina monista, la acción, en tanto que derecho al ejercicio de la actuación jurisdiccional no era sino una prolongación o manifestación del derecho material, entendido, en el momento del conflicto, como un «derecho en pie de guerra».

El origen de la concepción monista de la acción ${ }^{1}$, que se mantendrá hasta mediados del siglo XIX, se encuentra en el Derecho Romano - recuérdese que en Roma regía un auténtico sistema de acciones, puesto que "a cada actio le correspondía un derecho»: "Nihil aliud est actio quam ius quod sibi debeatur iudicio persequendi» ${ }^{2}$ - en el que el derecho de acción y el derecho subjetivo material no sólo se complementaban recíprocamente, como sucede en la actualidad, sino que se entremezclaban conformando un único derecho material de acción, dónde, una vez advertido el litigio, primero se entablaba la acción y sólo más tarde, el derecho subjetivo vendría a regular el contenido material del procedimiento creado, en exclusiva, para ese concreto derecho sustantivo.

La nítida diferencia entre el Derecho objetivo, entendido en el momento presente como el «conjunto de normas jurídicas generales, imperativas y coercibles» —estas normas nos dicen, a modo de ejemplo, quién puede ser considerado propietario, usufructuario, acreedor, heredero, etc. - y los derechos subjetivos, entendidos como "cualidades morales atribuidas a una persona para tener o hacer algo justamente»o, en su caso, como «situaciones de poder o de

1 El máximo exponente de la concepción monista de la acción podemos encontrarlo no sólo el Derecho romano, que regula un sistema de acciones, sino también en SAVIGNY (la acción es el aspecto bajo el que se nos presenta el derecho subjetivo cuando ha sido violado, es un momento del derecho subjetivo), PUCHTA (la acción es el derecho subjetivo en pie de guerra); UNGER (la acción es el derecho que abandona la toga para ponerse el sagum - la capa militar -); la escuela francesa (con expresiones tales como "si no hay derecho, no hay acción»; "no hay derecho sin acción» $\mathrm{y}$ "no acción sin derecho»), los autores españoles del siglo XIX y el propio WINDSCHEID, que fue, según nuestra fuente, el último autor monista, inmediatamente antes de que MUTHER concibiese, por vez primera, la concepción dualista de la acción. Para un estudio pormenorizado, se remite al lector a MONTERO AROCA, J., «Derecho Jurisdiccional», Parte General, Ed. Tirant lo blanch, Valencia, 2003, pp. 238 a 241.

2 Este aforismo romano expresa el máximo exponente de la concepción monista de la «acción» en la que a cada acción corresponde un derecho, conformando ambas el «sistema de acciones» que regía en Roma por contraposición al actual «sistema de derechos». 
preferencia respecto de cosas o contra personas» ${ }^{3}$-así, los propietarios, usufructuarios, acreedores y herederos son titulares de derechos subjetivos- no existía en Roma.

Esta ausencia de diferenciación entre el Derecho objetivo y los derechos subjetivos supuso la fusión - y confusión- entre derecho de acción y derecho subjetivo material. El derecho de acción fue concebido, en este sentido, como el «mecanismo», la "forma», el «modo» o, si se quiere, la «manera» de poner en práctica o de hacer efectivo el derecho subjetivo material, siempre posterior, aún cuando fundido en él, al derecho de acción.

La unificación del derecho material y de la acción procesal no resultó, sin embargo, defendible, durante mucho tiempo y ello debido, conforme ha tenido ocasión de señalar GUASP ${ }^{4}$, a que la acción y el derecho no coinciden ni en cuánto a los sujetos, ni en cuánto al contenido, ni en cuánto a los efectos ${ }^{5}$.

La distinción entre derecho subjetivo material y derecho de acción es obra de MUTHER, quién, en plena polémica con WINDSCHEID, destacó que, aún cuando la actio romana era un prius respecto del derecho subjetivo material, a diferencia de lo que acontece en la actualidad -dónde es un posterius - lo cierto es que el derecho subjetivo material se dirige contra un particular y tiene naturaleza privada, mientras que el derecho de acción se dirige contra el Estado, personalizado en sus órganos jurisdiccionales, y tiene naturaleza pública ${ }^{6}$.

La concepción dualista de la acción surge, al fin, con la nítida distinción entre el derecho de acción y el derecho subjetivo material. La vigencia de esta concepción perdurará, con alguna excepción, hasta nuestros días.

${ }^{3}$ Las definiciones transcritas en el texto son de MONTERO AROCA, J., «Derecho Jurisdiccional», Parte General, cit., p. 238.

${ }^{4}$ Vid., GUASP, J., «Derecho Procesal Civil», Tomo I, Introducción y parte general, Instituto de estudios políticos, Madrid, 1968, p. 213.

5 En este sentido, resulta evidente que la acción existe porque existe la Jurisdicción, no siendo, sin embargo, el órgano jurisdiccional, el destinatario del derecho, que lo es, en verdad, el sujeto materialmente obligado a cumplir el dictado de la norma sustantiva, a quién corresponde, en su caso, ocupar el rol de «sujeto pasivo», en el proceso que llegue a entablarse. El contenido del derecho viene constituido por una prestación material, mientras que el propio contenido de la acción vendrá, sin embargo, integrado por la actuación de los órganos jurisdiccionales. Finalmente, los efectos del derecho material podrán obtenerse o no, pero los efectos de la acción, instrumentada a través del proceso, se obtendrán siempre y en todo caso.

6 Vid., MONTERO AROCA, J., «Derecho Jurisdiccional», Parte General, cit., p. 241. 
Conviene poner de manifiesto, antes de adentrarnos en el estudio de la acción ${ }^{7}$, que las distintas teorías de la referida acción han girado, indefectiblemente, sobre el estudio del derecho privado, de tal suerte que los resultados de este debate, con alguna aislada excepción $^{8}$, no podrían resultar extensibles al ámbito del derecho penal. Y ello es así debido a la circunstancia de que el ius puniendi corresponde, en exclusiva, al Estado ${ }^{9}$, quedando, en consecuencia, fuera del poder de disposición de los particulares, quiénes no tienen derecho alguno a la imposición de la pena. La inexistencia de un derecho subjetivo material a la imposición de la pena no nos permite, en conclusión, integrar la dogmática del Derecho penal en las distintas teorías de la acción civil.

7 Las concepciones de la acción analizadas en este trabajo corresponden a los autores españoles. Sin perjuicio de ello, nos parece interesante señalar que CHIOVENDA, G., define la acción como «il potere giuridico di porre in essere la condizione per l'attuazione della volontà della legge» ( el poder jurídico de dar vida a la condición para la actuación de la ley por el órgano jurisdiccional), en «Principi di Diritto Processuale Civile. Le azioni. Il processo di cognizione», Ed. E. Jovene, Napoli, 1980, p. 45; ARELLANO, C., apunta que "el derecho de acción no es la prerrogativa a la sentencia favorable pero sí es la facultad que conduce a todo el procedimiento jurisdiccional hasta la sentencia y aún, en su caso, hasta la ejecución forzada de lo fallado», en "Teoría general del proceso», Ed. Porrua, México D.F., 1980, p. 257; MONTESANO, L., por su parte, sin llegar elaborar, propiamente, un concepto de acción, acomete un estudio detenido de este derecho en "La tutela giurisdizionale dei diritti», Tomo $4 .^{\circ}$ del «Trattato di Diritto Civile italiano», Ed. Utet, Torino, 1985, pp. 87 y ss.

8 Así, el concepto de «acción» elaborado por FAIRÉN es válido tanto para la «acción civil» como para la "penal», diferenciándose ambos tipos de acciones, como se verá más adelante, tan sólo por la pretensión que se ejercite en cada una de ellas; MONTERO, por su parte, nos explica, tal y como luego expondremos con mayor detenimiento, que la "acción» — sea civil o penal- triunfa siempre, entre tanto el éxito de la pretensión se hace depender de la legitimación y de la fundamentación.

9 Sin perjuicio de esta afirmación generalmente aceptada — el ius puniendi corresponde, en exclusiva, al Estado- conviene precisar que no todos los autores admiten que el Estado tenga derecho a castigar. En concreto, MANZINI manifestó, en su momento, que no existía tal derecho subjetivo del Estado, sino que la facultad de penar era un atributo de su soberanía; y JIMÉNEZ DE ASÚA, L., de quién hemos tomado la anterior cita en la obra que señalamos en esta nota - p. 21- ha afirmado, por su parte, que «cuando el Estado impone una sanción, canaliza así los instintos ancestrales del hombre: la retribución, la venganza y el sadismo.(...).Interesa subrayar que la pena es la compensación de la renuncia al sadismo. El hombre de antaño satisfacía su instinto de crueldad con mil espectáculos cotidianos. Al de hoy apenas si le quedan algunas diversiones que, como las corridas de toros, el boxeo, las peleas de gallos y el castigo de los delincuentes. Todos estos instintos ancestrales han canalizado el derecho a penar», en «Principios de Derecho Penal. La Ley y el delito», Ed. AbeledoPerrot, 3. ${ }^{\text {a }}$ ed., Buenos Aires, 1958, p. 41. 


\section{Teoría concreta}

A. GÓMEZ ORBANEJA, E.: «La acción es: a) un derecho concreto; b) de contenido determinado; c) de naturaleza pública» ${ }^{10}$.

La acción, según GÓMEZ-ORBANEJA ${ }^{11}$, no es el derecho a obtener una sentencia sino la sentencia favorable. El derecho de acción es previo al proceso y se ejercita por el acto procesal de interponer la demanda, en la que se hace valer este derecho a la sentencia en un sentido determinado.

La naturaleza pública del derecho de acción en sentido procesal se deriva, a juicio de este autor ${ }^{12}$, de que frente a él el obligado es el Estado (como depositario del poder jurisdiccional). El acto de tutela se pide, pues, siempre (del Estado) frente a un demandado, pero no necesariamente contra un obligado ${ }^{13}$.

B. DE LA OLIVA SANTOS, A.: «La acción es un derecho subjetivo público a una tutela jurisdiccional concreta ${ }^{14} »$.

La tesis defendida por el Profesor De la Oliva, en el marco la Teoría concreta de la acción ${ }^{15}$, podría sintetizarse en los siguientes puntos: En primer lugar, afirma que «los sujetos jurídicos no sólo tienen un derecho abstracto a pedir o a pretender, sino verdaderos derechos subjetivos concretos y materiales a obtener sentencias de contenido determinado o específico» ${ }^{16}$. A estos derechos subjetivos concretos y materiales les denomina acciones.

10 Vid., GÓMEZ ORBANEJA, E., «Derecho procesal civil», volumen primero, «Parte general. El proceso declarativo ordinario», 7. a ed., Madrid, 1975, p. 277.

11 GÓMEZ ORBANEJA, E., «Derecho procesal civil», volumen primero, p. 227.

12 GÓMEZ ORBANEJA, E., «Derecho procesal civil», volumen primero, pp. 227-8.

13 Vid., en este sentido, GÓMEZ ORBANEJA, E., la afirmación siguiente: «mientras que la pretensión del derecho civil va dirigida contra el sujeto pasivo de la relación, el obligado a satisfacerla mediante la prestación, la acción, es un derecho dirigido al Estado y que sólo el Estado puede satisfacer mediante sentencia», "Derecho procesal civil», volumen primero, p. 231.

${ }^{14}$ DE LA OLIVA SANTOS, A., "Derecho Procesal. Introducción», Ed. Ceura, 2. ed., Madrid, 2002, p. 85 .

15 Para un estudio pormenorizado sobre la «acción» en el marco de la teoría concreta, se remite al lector a la obra de DE LA OLIVA SANTOS, «Sobre el derecho a la tutela jurisdiccional. La persona ante la Administración de Justicia: derechos básicos», Ed. Bosch, Madrid, 1980.

${ }^{16}$ DE LA OLIVA SANTOS, A., «Derecho Procesal. Introducción», cit., p. 84. 
Esta reflexión inicial predetermina, como es lógico, el razonamiento siguiente, atinente al momento cronológico, dentro o fuera del «iter» procesal, en el que la acción tenga lugar. Así, este autor viene a señalar, en segundo lugar, que «el derecho en que consiste la acción es, en su existencia, anterior e independiente de todo proceso» ${ }^{17}$. Y ello es así, a juicio del Prof. De la Oliva, debido a la circunstancia de que la acción, entendida como derecho de contenido jurídico-material, existe cuando concurren determinados presupuestos de orden sustantivo, de tal suerte que, una vez advertida la efectiva concurrencia de dichos presupuestos materiales, el derecho de acción o derecho a una tutela jurisdiccional concreta es anterior al nacimiento del proceso e incluso independiente de su existencia, toda vez que el titular de los derechos enunciados puede renunciar al ejercicio del derecho al proceso, manteniendo, ello no obstante, su derecho de acción.

En tercer lugar, este autor, tras identificar, de manera muy gráfica los términos "acción» y "razón», explica que "cabe tener acción y no tener, sin embargo, derecho al proceso o a la inversa, tener este último y carecer de acción» ${ }^{18}$. La primera de las hipótesis recién expuestas es clara: si estimamos que el derecho al proceso es, conforme indica el autor ${ }^{19}$, el «derecho a una sentencia de fondo» cabe, en efecto, tener derecho a la acción y carecer, ello no obstante, del derecho al proceso, en aquellos supuestos en los que, ante la ausencia de determinados presupuestos procesales, no pueda el proceso finalizar con una sentencia de fondo, habiendo de conformarse el titular del derecho de acción con una resolución meramente procesal.

Así, pues, el Prof. De la Oliva acomete una nítida distinción entre el derecho de acción, cuyo éxito depende de la existencia de presupuestos jurídico-materiales anteriores e independientes de todo tipo de procesos y el derecho al proceso, cuya finalidad es la obtención de una sentencia de fondo, que, naturalmente, se hará depender de la concurrencia de los presupuestos procesales.

Finalmente, este autor razona, bajo la misma lógica argumental, que «si sólo se concediese derecho al proceso a quién tuviese en verdad la acción (derecho a la tutela jurisdiccional concreta) que afirma tener, estaríamos en una indisoluble aporía: antes del proceso o, al menos, antes de su final, tendríamos que saber quién tiene acción, que es justamente lo que en el proceso se intenta determinar (al final). De manera

17 DE LA OLIVA SANTOS, A., «Derecho Procesal. Introducción», cit., p. 85.

18 DE LA OLIVA SANTOS, A., «Derecho Procesal. Introducción», cit., p. 91.

19 DE LA OLIVA SANTOS, A., «Derecho Procesal. Introducción», cit., p. 90. 
que hay que resignarse ante la necesidad de conceder derecho al proceso a quién puede no tener acción (razón)».

Las críticas a esta concepción de la acción han sido muy variadas. Frente a muchas de ellas ha tendido ocasión de defenderse el Profesor de la Complutense. Así, pues, frente a la objeción referida a que si el derecho de acción es un derecho subjetivo-material no debiera ser afrontado su análisis en sede procesal, ha sostenido el autor que "si se puede pensar, simplemente, en la acción es por que existe la Jurisdicción, la Administración de Justicia, de la que se ocupa el Derecho Procesal $^{20}$.

Asimismo, frente a la crítica central formulada frente la Teoría concreta, atinente a que la acción, concebida como un derecho subjetivo-material, supone una incógnita, toda vez que su existencia no podrá afirmarse hasta el final del proceso, ha venido a señalar DE LA OLIVA $^{21}$ que «las cosas son lo que son y no lo que los Jueces (o los árbitros) dicen que son", a lo que añade que "los derechos subjetivos nacen o existen con independencia de que sean reconocidos como existentes por otros sujetos o por los Tribunales. De lo contrario, sería forzoso concluir que no hay más derechos (de cualquier tipo) que los que son reconocidos y que no existen sentencias injustas (ni siquiera habría parámetros para establecer lo justo o lo injusto)».

\section{Ensayo del concepto «acción».}

Frente a esta Teoría concreta de la acción nos parece imprescindible plantearnos una serie de cuestiones. El entendimiento "procesal» o "material» de la acción nos parece, en este sentido, enormemente relevante, pero no ya porque, de conceptuarlo como "procesal» gane, nuestra disciplina, una mayor autonomía. No sería lícito tratar de invadir campos ajenos por el sólo deseo de otorgar mayor enjundia a unas disciplinas frente a otras. El hecho de que pertenezca a una o otra rama del ordenamiento resulta, asimismo, insignificante, frente a la necesidad científica de razonar debidamente el concepto y, llegado el momento, alcanzar, al fin, un consenso doctrinal, que ponga fin a más de un siglo y medio de debate.

Nuestra primera incógnita viene, pues, determinada por el interrogante a propósito de si el concepto de la «acción»supone, para los

${ }^{20}$ DE LA OLIVA SANTOS, A., «Derecho Procesal. Introducción», cit., p. 86.

21 DE LA OLIVA SANTOS, A., «Derecho Procesal. Introducción», cit., p. 88-9. 
distintos autores implicados en tan arduo debate, una mera diferencia terminológica o, en efecto, del contenido que, en definitiva, se integre en dicho concepto, resultan notables resultados contradictorios en la práctica. Si este interrogante se despejase en favor de la primera de las soluciones expuestas, entonces no resultaría económico, para los estudiosos, invertir más tiempo en el análisis de un concepto, cuya elaboración debiera ser, en tal caso, acometida con tintes de generalidad y, en consecuencia, comprensiva de todos los puntos de vista manifestados por los distintos autores.

Este concepto, nos atrevemos a señalar, podría ser el siguiente: la acción es un derecho: a) subjetivo, por cuánto pertenece a todo sujeto de derecho; b) de contenido procesal, en tanto en cuánto debe ejercitarse en el marco del proceso y la sentencia de fondo que llegue a conceder la tutela solicitada precisa de la concurrencia de una serie de presupuestos procesales, sin los cuales la relación jurídico-material quedaría imprejuzgada y c) de contenido material, en la medida en la que aquella sentencia de fondo, favorable a la pretensión del actor, tampoco sería posible, en tal caso, sin la preexistencia de otra serie de presupuestos materiales, incardinados en otras ramas del ordenamiento, perfectamente delimitadas respecto de nuestra disciplina de conocimiento, de cuyo análisis, al igual que del de los presupuestos procesales anteriormente enunciados y por el orden cronológico expuesto en este ensayo de «concepto», se ocupan los Jueces y Magistrados.

Así entendida la «acción», resulta lógico afirmar que el estudio de su concepto y fundamento concierne tanto a los constitucionalistas, en su dimensión o alcance de derecho fundamental; como a los procesalistas, en el seno del proceso; y, naturalmente, a los civilistas, mercantilistas, administrativistas, penalistas y, en fin, laboralistas, en el marco del derecho sustantivo subyacente en las distintas pretensiones de tutela judicial efectiva ${ }^{22}$.

Ahora bien, la proyección procesal que se otorga al concepto de «acción» parece cerrar toda posibilidad de conferirle, al propio tiempo, un alcance material. Y, en este sentido, frente a los defensores de la Teoría concreta, que identifican la «acción» con el derecho material susceptible de una concreta y específica tutela, se alzan los de la Teoría abstracta, que identifican la "acción» con el derecho de acceso a los Tribunales de Justicia. Naturalmente, para los primeros el derecho

${ }^{22}$ Para un estudio sobre la diferencia entre las pretensiones materiales y las pretensiones procesales, se remite al lector al estudio de GUIMARÀES RIBEIRO, D., "La pretensión procesal y la tutela judicial efectiva», Ed. Bosch, Barcelona, 2004, pp. 203 y ss. 
de «acción» se tiene o no se tiene, pero, de tenerse, se tiene con independencia del proceso. Para los segundos, sin embargo, el derecho de "acción» se tiene, siempre y en todo caso, pues corresponde a todo sujeto con capacidad para ser parte, si bien este derecho comprende, frente a la facultad, de los particulares, de pedir una concreta tutela judicial, la obligación, de los Tribunales de Justicia, de dar respuesta motivada a dicha petición. Esta respuesta puede ser, naturalmente, de fondo o meramente procesal y, en el primero de los supuestos, favorable o contraria a los intereses del solicitante de la tutela.

Para despejar la incógnita de nuestro primer interrogante no ha bastado, en línea de principio, el intento de un concepto comprensivo de ambas Teorías, puesto que la proyección práctica, que dimana de cada una de ellas, parece excluyente. No podemos afirmar que el derecho de acción es anterior e independiente de todo proceso y señalar, al propio tiempo, que el derecho de acción es el derecho de solicitar, ante los Tribunales de Justicia, en el marco del proceso, la tutela de nuestras pretensiones.

Así, pues, y dado que no se trata de una concepción meramente terminológica, nos adentramos en el terreno de la práctica con un segundo interrogante: si la acción se tiene cuando concurren determinados presupuestos materiales, si la acción se tiene, una vez confirmada la concurrencia de dichos presupuestos, con independencia del proceso, entonces nos preguntamos ...¿quién examina la existencia de estos presupuestos? ¿quién, tras su examen, determina que, en efecto, dichos presupuestos son los requeridos para afirmar, en el caso concreto, la existencia de la «acción»? y, finalmente, ¿quién confiere dicho derecho de acción a los particulares? ...Ante estos interrogantes, nos preguntamos, de nuevo, a modo de respuesta ...¿ंson los propios particulares quiénes se auto-adjudican su particular «derecho de acción»? ¿son sus abogados quiénes estiman que concurren los presupuestos materiales establecidos por los códigos sustantivos para conferir, a sus clientes, dicho derecho de acción? ...si el derecho de acción es anterior e independiente del proceso no podemos afirmar que sean los Jueces quiénes vengan destinados a conceder la «razón-acción» a los particulares...Sus razones-acciones son anteriores a la existencia misma del proceso, no lo olvidemos.

La acción, entendida como «razón», se tiene o no se tiene, y desde luego así nos lo parece, al margen del proceso. La acción-razón, una vez confirmada su existencia positiva, se tiene, desde luego, con independencia del proceso. Asimismo, la acción-razón permanece con independencia del fracaso, en el proceso, del titular de esa acción-ra- 
zón. Y ello es tan evidente en el supuesto del fracaso por una resolución amparada en la existencia de óbices procesales, como en el de un fallo motivado de contenido material, que, debido a la falibilidad humana, viene a negar la realización material de la Justicia, a quién debiera serle concedida, por estar «cargado de razones-acciones» para ello. Ahora bien, la mera existencia de la acción a favor de quién, ello no obstante, ha visto rechazada, en los Tribunales, su pretensión no parece añadir nada a su existencia, puesto que la «acción» no le permitirá, una vez desestimada o rechazada su concreta petición, en la práctica, operar como si, en otro caso, se hubiere declarado su derecho, constituido su nueva situación jurídica o, en su caso, condenado a la contraparte al «hacer»o «no hacer» reclamado, en el proceso, por el actor que, pese a tener «acción-razón» ha visto rechazada su pretensión.

\section{Manifestaciones de la teoría concreta en la LEC 1/2000.}

La LEC 1/2000 mantiene, como es sabido, la Teoría concreta de la acción. No pretendemos acometer, en este momento, una enumeración exhaustiva de todos y cada uno de los preceptos procesales civiles en los que pueda observarse la adhesión a dicha Teoría pero sí nos parece conveniente resaltar, de manera ilustrativa, algunas de sus más explícitas manifestaciones.

El artículo $20.1^{\circ}$ LEC establece que «cuando el actor manifiesta su renuncia a la acción ejercitada o al derecho en que funde su pretensión, el Tribunal dictará sentencia absolviendo al demandado, salvo que la renuncia fuese legalmente inadmisible». Esta concepción de la acción como derecho de contenido concreto no puede admitirse desde la concepción abstracta de la acción, secundada por un amplio sector de la doctrina, toda vez que la renuncia a la acción sería, según han argumentado, un acto nulo, si tomamos en consideración que nadie puede renunciar a su derecho a acudir a los Tribunales. En realidad, la renuncia, como medio de finalización del proceso, tiene por objeto el derecho subjetivo material que fundamenta la pretensión y la pretensión misma ${ }^{23}$.

${ }^{23}$ Vid., GIMENO SENDRA, V., quién, asimismo, advierte que la renuncia puede conceptuarse como «un acto unilateral del demandante por el que decide abandonar su derecho subjetivo o derecho a pretender y, por tanto, la pretensión, provocando la finalización anormal del proceso mediante la emisión de una resolución jurisdiccional que ha de gozar de todos los efectos de la cosa juzgada», en "Derecho procesal civil», Tomo I, Ed. Colex, Madrid, 2009, p. 248. 
El capítulo I del Título III, correspondientes al Libro I (arts. 7173), se refiere a la «acumulación de acciones»y, en este sentido, el artículo $71.2^{\circ}$ establece que «el actor podrá acumular en la demanda cuántas acciones le competan contra el demandado, aunque provengan de diferentes títulos, siempre que aquellas no sean incompatibles entre sí». Esta acumulación de acciones, según la LEC, en verdad lo es de pretensiones, a juicio de un sector mayoritario de nuestra doctrina $^{24}$, y su fundamento hay que encontrarlo tanto en razones de economía procesal, como, en último término, en el derecho a la tutela judicial efectiva.

\section{Teoría abstracta}

Los autores de la Teoría abstracta han sido enumerados, en el presente trabajo, por un orden estrictamente cronológico. Este orden de aparición, resultado del anterior orden en el que han sido estudiados por quién suscribe estas líneas, nos permite, de un lado, conocer la autoría de los avances producidos en la evolución del concepto, toda vez que las «repeticiones» de ideas originales o «citas de citas» pueden resultar muy perniciosas y, de otro, analizar las reflexiones surgidas al hilo de dicha evolución en orden a rescatar sus mejores resultados para encuadrarlos en el concepto de «acción» a que aspira este ensayo.

A. GUASP, J.: Concebido por el Estado el poder de acudir a los Tribunales de Justicia para formular pretensiones: derecho de acción, el particular puede reclamar cualquier bien de la vida, frente a otro sujeto distinto, de un órgano jurisdiccional; pretensión procesal, iniciando para ello mediante un acto específico: demanda, el correspondiente proceso, el cual tendrá como objeto aquella pretensión ${ }^{25}$.

GUASP $^{26}$ ha partido, en la elaboración de su concepto de «acción» de una crítica a la teoría concreta, caracterizada, como es sabido, entre otras notas, por la identificación del derecho de acción con el derecho a obtener una sentencia de contenido favorable. En

\footnotetext{
${ }^{24}$ Vid., por todos, GIMENO SENDRA, V., «Derecho procesal civil», Tomo I, op. cit., p. 226.

${ }_{25}$ Vid., GUASP, J., «Derecho Procesal Civil», Tomo I, Introducción y parte general, Instituto de estudios políticos, Madrid, 1968, p. 216.

${ }_{26}$ GUASP, J., «Derecho Procesal Civil», Tomo I, pp. 214-5.
} 
este sentido, el referido autor ha manifestado que no puede afirmarse que en todo proceso exista un derecho previo al mismo que permita exigir fundadamente una resolución de contenido determinado y favorable, pues puede muy bien ocurrir que el promotor del proceso carezca de este derecho, sin que por ello sea posible sostener que el proceso se ha desarrollado en el vacío.

El derecho de acción como derecho a una resolución justa sin más ha sido, asimismo, concebido por GUASP ${ }^{27}$, como un derecho $-\mathrm{O}$, si se quiere, mera facultad, si bien entendida ésta como manifestación secundaria de un derecho más amplio, v.g., del derecho constitucional de petición- de carácter público e independiente, pero no será previo al proceso, sino que nacerá con la demanda judicial. Es por ello por lo que nos habla este autor de la «relatividad» e «intrascendencia» del concepto de acción, para la resolución de problemas puramente procesales, frente a la pretensión, que, fundida o no, en cuánto al trámite, con la demanda, es el auténtico objeto del proceso, el concepto que establece el ámbito dentro del cual el proceso vive, la materia procesal por antonomasia.

La pretensión, finalmente, es, según GUASP ${ }^{28}$, una declaración de voluntad - porque en ella se expone lo que el sujeto quiere-, mediante la cual el pretendiente reclama una cierta actuación del órgano judicial - y en ello la pretensión procesal se distingue de la civil, que tiene siempre por destinatario a un particular-, frente a persona determinada y distinta del autor de la reclamación — pues, en otro caso carecería de la dimensión social que el derecho exige para concederle el tratamiento procesal adecuado-.

B. FAIREN GUILLÉN, V.: «Concebimos a la acción como el derecho de excitar la actividad jurisdiccional del Estado; se trataría de un derecho público, subjetivo procesal; de un «derecho cívico» ${ }^{29}$.

Del concepto de «acción», elaborado por FAIREN, destacamos las siguientes notas:

En primer lugar, FAIREN ${ }^{30}$ considera que la «acción» es una manifestación del derecho de petición. Es el derecho — abstracto- del

\footnotetext{
27 GUASP, J., «Derecho Procesal Civil», Tomo I, pp. 215-6.

28 GUASP, J., «Derecho Procesal Civil», Tomo I, p. 217.

29 Vid., FAIREN GUILLÉN, V., «Temas del ordenamiento procesal», Tomo I, Historia. Teoría General, Ed. Tecnos, Madrid, 1969, pp. 306-7.

30 FAIREN GUILLÉN, V., «Temas del ordenamiento procesal», cit., pp. 308-9.
} 
ciudadano - a quién, por cierto, hay que conceder dicho acceso a los Tribunales con la máxima generosidad- de acudir a la autoridad judicial con el propósito de presentar un conflicto y pedir que lo resuelva, correlativo al deber, de los Jueces, de resolver, tanto en el orden civil como en el penal, este conflicto, incurriendo, en otro caso, en una falta de responsabilidad.

En segundo lugar, distingue el antiguo Profesor de la Autóno$\mathrm{ma}^{31}$, el concepto de "acción» del de "pretensión», exponiendo, de manera muy gráfica, que la acción triunfa siempre y no ocurre así con la pretensión ${ }^{32}$.

La acción corresponde a todos los ciudadanos, y ante todos se da la obligación del Estado (asumida a través de sus órganos jurisdiccionales) de examinar si hay en ellos potestad para acoger la que se promovió, de tal suerte que la acción logra su finalidad (poner en movimiento jurisdiccional al Estado), sea quién sea el que la proponga, en tanto tenga capacidad para ser parte, puesto que el Tribunal habrá de resolver sobre ella en todo caso. Sin embargo, la eficacia de la pretensión está condicionada, de un lado, por la legitimación ( es decir, por la necesidad de que el que "pretenda» se halle en determinada relación con el interés que alega como violado) y, de otro, por la fundamentación.

Finalmente, la concepción de la acción, expuesta por FAIREN ${ }^{33}$, puede aplicarse al proceso penal, en dónde las diferencias halladas con respecto a la «acción civil» serían en realidad, según el propio autor, diferencias entre las dos pretensiones.

C. PRIETO-CASTRO Y FERRÁNDIZ, L.: «La acción es el instrumento de ejercicio del derecho a la justicia que en el orden jurídico privado corresponde a toda persona (excepto los casos expresamente excluidos) frente al Estado (que instituye órganos jurisdiccionales) y contra otro sujeto, para provocar la incoación de un proceso y la correspondiente decisión sobre un objeto de derecho privado o procesal» ${ }^{34}$.

31 FAIREN GUILLÉN, V., «Temas del ordenamiento procesal», cit., pp. 310-311.

32 Para un estudio pormenorizado sobre la pretensión en el pensamiento de FAIRÉN GUILLÉN, V., se remite al lector a su trabajo, «De nuevo sobre los conceptos de acción y de pretensión", Revista de Derecho Procesal, n. ${ }^{\circ} 1,1988$, pp. 18 y ss.

33 FAIREN GUILLÉN, V., «Temas del ordenamiento procesal», cit., p. 312.

34 Vid., PRIETO-CASTRO Y FERRÁNDIZ, L., «Tribunales españoles. Organización y funcionamiento», Ed. Tecnos, Madrid, 1973, p. 102. 
El concepto de «acción» elaborado por PRIETO-CASTRO ${ }^{35}$, en el orden civil, comprende, muy sintéticamente expuestas, las siguientes notas:

En primer lugar, la acción no es una facultad desvinculada de toda base jurídico-material ( o procesal), es decir, no es un derecho abstracto que corresponde a cualquiera, con independencia de que pueda invocar, o no, un sustrato de hechos y una norma jurídica que asocie a estos hechos, determinados efectos jurídicos. La petición de justicia mediante una acción exige, según este autor ${ }^{36}$, la invocación de una causa que se compone de los hechos y de los fundamentos de derecho, y la de un interés en lograr la decisión jurisdiccional, porque de otro modo no podría obtener satisfacción su derecho.

En segundo lugar, la acción se hace valer frente al Estado y no contra el Estado ${ }^{37}$, toda vez que los órganos jurisdiccionales por él instituidos no pueden suministrar al accionante, con la sólo excepción de las acciones mero-declarativas y cautelares, el bien concreto que constituye el objeto del proceso. La acción corresponde, pues, a toda persona contra otro sujeto, habiendo de gozar ambas, de la respectiva legitimación activa y pasiva, según enseña la teoría de la legitimatio ad causam.

En tercer lugar, la acción tiene una dirección bilateral, que permite y obliga a condenar o a absolver al demandado, según la situación favorable o desfavorable que cada una de las partes se haya creado en el proceso, con sus alegaciones, sus pruebas y la exoneración de las cargas procesales ${ }^{38}$.

Finalmente, la acción supone la existencia de un objeto, material o procesal, propuesto por el accionante. El objeto inmediato de la acción es el otorgamiento de la propia acción, que se produce por la aplicación al caso concreto de las normas que constituyen el ordenamiento jurídico. El objeto mediato es la satisfacción del derecho o interés, reconocidos por las normas ${ }^{39}$.

35 Para un estudio comprensivo de todas las proyecciones o manifestaciones del derecho de acción según PRIETO-CASTRO Y FERRÁNDIZ, L., se remite al lector, al trabajo de este autor titulado "El derecho a la tutela jurisdiccional», en "Jornadas de Derecho procesal», Consejo General del Poder Judicial, Madrid, 1984, pp. 13 a 25.

36 PRIETO-CASTRO Y FERRÁNDIZ, L., «Tribunales españoles. Organización y funcionamiento», cit., pp. 102 y 103.

37 PRIETO-CASTRO Y FERRÁNDIZ, L., «Tribunales españoles. Organización y funcionamiento», cit., p. 103.

38 PRIETO-CASTRO Y FERRÁNDIZ, L., «Tribunales españoles. Organización y funcionamiento», cit., p. 103.

39 PRIETO-CASTRO Y FERRÁNDIZ, L., «Tribunales españoles. Organización y funcionamiento», cit., pp. 105-6. 
El concepto de «acción», elaborado por PRIETO-CASTRO ${ }^{40}$, en el orden penal, coincide en su primer enunciado con el estudiado en el orden civil («la acción es también el instrumento de ejercicio del derecho a la justicia»), si bien difiere del mismo, principalmente, en la iniciación del proceso penal (por medio del M.F. o dando entrada al ejercicio de la acción a todos los ciudadanos y al ofendido), dirigida no contra otro sujeto sino contra el Estado, puesto que a él corresponde el derecho a castigar o ius puniendi.

D. MONTERO AROCA, J.: «La acción es el derecho de acudir a los órganos jurisdiccionales del Estado para interponer pretensiones o para oponerse a ellas» ${ }^{41}$.

El concepto procesal de «acción» elaborado por MONTERO aspira a servir de referencia tanto para el proceso civil como para el penal.

El Profesor de Valencia ${ }^{42}$ parte, en la elaboración de su concepto de «acción» de la distinción entre ésta, que es, a su juicio, un derecho que, ejercitado por persona capaz, triunfa siempre y la pretensión, a la que define como una declaración de voluntad petitoria, que tan sólo será estimada si concurren la legitimación y la fundamentación.

El ejercicio del poder de la acción comportará la existencia del derecho subjetivo público (y no privado, en razón a su sujeto pasivo) de acción en el particular y la obligación correlativa en el Juez o en el órgano jurisdiccional.

El Estado es, pues, a juicio de MONTERO ${ }^{43}$, el destinatario de la acción, sobre todo si se tiene en cuenta la posibilidad de que el Juez cambie a lo largo del proceso. La bilateralidad de la acción (entendida, en este momento, como existencia de dos derechos correlativos, - -acción y excepción- que se complementan y tienen una misma naturaleza, o bien la existencia de un derecho único que recibe nombres diferentes según la posición procesal de la persona que lo ejercita) ha

40 PRIETO-CASTRO Y FERRÁNDIZ, L., «Tribunales españoles. Organización y funcionamiento», cit., p. 107.

41 Vid., MONTERO AROCA, J., «Introducción al Derecho Procesal (Jurisdicción, acción y proceso)», Ed. Tecnos, Madrid, 1976, p. 151.

${ }^{42}$ MONTERO AROCA, J., «Introducción al Derecho Procesal (Jurisdicción, acción y proceso)», cit., pp. 151-2.

${ }^{43}$ MONTERO AROCA, J., «Introducción al Derecho Procesal (Jurisdicción, acción y proceso)», pp. 159-161. 
impulsado, a este autor ${ }^{44}$, a considerar que la acción, sin dejar de ser un derecho, se presenta también como una carga, puesto que - salvando la autocomposición, posible sólo en algunos casos- es el único camino que queda al particular para la defensa de sus intereses.

E. ALCALÁ-ZAMORA Y CASTILLO, N.: «Por acción debe entenderse la posibilidad jurídicamente encuadrada de recabar los proveimientos jurisdiccionales necesarios para obtener el pronunciamiento de fondo y, en su caso, la ejecución, respecto de una o más pretensiones litigiosas ${ }^{45}$.

Los elementos de la acción son, a juicio de ALCALÁ-ZAMORA ${ }^{46}$, tres: uno subjetivo, la capacidad de accionar, y dos objetivos: el primero, la instancia, esto es, la energía impulsora que permite recabar las resoluciones reputadas necesarias por las partes para la marcha del proceso, desde las providencias de trámite hasta la sentencia final; y el segundo, la pretensión, es decir, la carga o peso que aquélla arrastra hacia el pronunciamiento de fondo o, si se prefiere, la visión del litigio que aduce el accionante.

ALCALÁ-ZAMORA nos habla de «accionante» y no de «actor» porque, de acuerdo con el planteamiento dinámico del proceso que propugna, como regla ambas partes accionan, aunque en ocasiones el titular pasivo no lo haga. De este modo, a la acción, según prosigue este Profesor ${ }^{47}$, se opone a la reacción y se contrapone la inacción.

F. GIMENO SENDRA, V.: «La acción es el derecho subjetivo público de carácter constitucional consistente en poner en poner en funcionamiento la actividad jurisdiccional del Estado» ${ }^{48}$.

Del concepto de la «acción» elaborado por GIMENO hemos de destacar las siguientes notas:

${ }^{44}$ MONTERO AROCA, J., «Introducción al Derecho Procesal (Jurisdicción, acción y proceso)», p. 164 .

45 Vid., ALCALÁ-ZAMORA Y CASTILLO, N., «Nuevos estudios de Derecho Procesal», Ed. Tecnos, Madrid, 1980, p. 45.

${ }^{46}$ ALCALÁ-ZAMORA Y CASTILLO, N., "Nuevos estudios de Derecho Procesal», cit., p. 45. p. 45 .

ALCALÁ-ZAMORA Y CASTILLO, N., «Nuevos estudios de Derecho Procesal»,

48 Vid., GIMENO SENDRA, V., «Fundamentos del Derecho Procesal (Jurisdicción, acción y proceso)», Ed. Civitas, Madrid, 1981, p. 130. 
En primer lugar, afirma GIMENO ${ }^{49}$ que el derecho de acción, como lógica consecuencia del principio de «igualdad de todos los ciudadanos ante la Ley», es un derecho subjetivo público porque se concreta en un poder que asiste a todo ciudadano, mediante el cual puede obligar al órgano jurisdiccional, por razón de su «oficio»y no por una supuesta relación jurídica con las partes, a emitir un pronunciamiento, a través de una resolución motivada, sobre una determinada petición, que, naturalmente, podrá admitirla o, en su caso, desestimarla.

En segundo lugar, el Profesor de la UNED ${ }^{50}$ estima que el derecho de acción es un derecho público de carácter constitucional debido a la circunstancia de que el Estado ha asumido en régimen de monopolio, como consecuencia de la prohibición de la autotutela, la función de administrar justicia, que, como principio inherente a la organización del Estado, alcanza una dimensión constitucional.

Finalmente, la acción, como derecho subjetivo público que asiste a todo ciudadano frente al Estado, se ejercita y agota, según GIME$\mathrm{NO}^{51}$, al poner en marcha la actividad jurisdiccional ${ }^{52}$, esto es, al crear en el Juez la obligación de carácter "público» de dictar una resolución de determinado contenido sobre la petición de apertura del proceso. La acción se diferencia de la pretensión en que el «derecho de pretender» se ejerce mediante una declaración de voluntad, la pretensión, que se deduce ante el Juez, pero se dirige contra el adversario, haciendo nacer en él la carga de contestar u oponerse a ella.

\section{Teoría ecléctica}

Una vez expuestas las principales líneas de pensamiento de los autores de las Teorías concreta y abstracta, surgidas durante los últimos

${ }^{49}$ GIMENO SENDRA, V., «Fundamentos del Derecho Procesal (Jurisdicción, acción y proceso)», cit., pp. 130 Y 131.

50 GIMENO SENDRA, V., «Fundamentos del Derecho Procesal (Jurisdicción, acción y proceso)», cit., p. 131.

51 GIMENO SENDRA, V., «Fundamentos del Derecho Procesal (Jurisdicción, acción y proceso)», cit., p. 133-4.

${ }_{52}$ Vid., en este sentido, GIMENO SENDRA, V., quién advierte que «si se parte de un concepto abstracto del derecho de acción, como hacemos nosotros, el objeto del proceso no lo constituye la acción (tal como afirman los partidarios de la teoría concreta), que, entendido como derecho de libre acceso a la Jurisdicción a fin de obtener una resolución fundada, motivada y congruente, se erige en el motor del proceso, pero no en su objeto, el cual viene determinado por la pretensión», "Comentario al artículo 5 de la Ley de Enjuiciamiento Civil», en «Proceso Civil Práctico», Ed. La Ley, Madrid, 2009. 
cuarenta años en España, nos parece conveniente acometer, de la mano de los partidarios de posiciones eclécticas, la labor de conciliar las doctrinas más verosímiles de cada una de aquellas teorías.

En este sentido, FENECH ${ }^{53}$ ha señalado que la acción es un derecho de carácter público, frente al Estado, que tiene como contenido la obtención de una sentencia que contenga la tutela jurisdiccional concreta.

Aún cuando FENECH parte de una concepción concreta de la acción ( derecho a la sentencia que contenga la tutela jurisdiccional concreta), lo cierto es que no podemos integrar su razonamiento dentro de la Teoría concreta, debido a que los estudiosos que conforman esta doctrina coinciden en señalar que la acción es anterior e independiente del proceso, y FENECH ${ }^{54}$, sin embargo, advierte que «el Juez o Tribunal tiene el deber de dictar sentencia definitiva otorgando la tutela concreta solicitada siempre que concurran los presupuestos, requisitos y condiciones procesales y los establecidos en el derecho material».

Asimismo, GÓMEZ-COLOMER ${ }^{55}$, por su parte, trata de conciliar ambas teorías, con advertencia expresa de que cada una de ellas pone de manifiesto un problema distinto, siendo ambas correctas y perfectamente complementarias. Entre tanto el derecho de acción viene referido, para la teoría concreta, a la victoria en el proceso; dicho derecho de acción explica, sin embargo, conforme a la teoría abstracta, el derecho a provocar la actuación jurisdiccional.

\section{A modo de conclusión sobre la acción y la defensa. La pretensión. Apuntes para un concepto.}

La acción surge necesariamente como consecuencia de la preexistencia de una relación jurídico-material. La relación jurídico-material, de la que participan dos o más sujetos, está compuesta por un número indeterminado de acciones, según cual sea la naturaleza de su relación (así, a modo de ejemplo, desde una compraventa hasta un homicidio frustrado). La relación jurídico-procesal puede estar com-

\footnotetext{
53 Vid., FENECH, M., «Derecho Procesal Civil. Introducción. Procedimientos ordinarios de declaración y de ejecución», Ed. Agesa, Madrid, 1983, p. 26.

54 Vid., FENECH, M., «Derecho Procesal Civil. Introducción. Procedimientos ordinarios de declaración y de ejecución», cit., p.27.

${ }_{55}$ GÓMEZ COLOMER, J. L., "Reflexiones sobre las bases científicas de la parte general del Derecho Jurisdiccional», en «Estudios de Derecho procesal en honor de Víctor FAIRÉN Guillén», Ed. Tirant lo blanch, Valencia, 1990, p. 261.
} 
pensada (así, el comprador paga el precio y el vendedor entrega la cosa), en cuyo caso cada sujeto ha llevado a cabo las «acciones» materiales que debía y no resulta precisa la actuación del derecho en su vertiente judicial. La relación jurídico-procesal, sin embargo, puede estar descompensada (así, el vendedor que ha entregado la cosa, frente al comprador que no ha pagado el precio o, en su caso, la víctima del homicidio frustrado frente al agresor).

Cuando la relación jurídico-material se encuentra descompensada y la naturaleza de dicha relación es de derecho privado, hemos de distinguir entre aquellos supuestos en los que el «interés» alcanza tan sólo a los particulares implicados en dicha relación y aquellos otros en los que más allá de dicho "interés» particular, existen «intereses generales» o «intereses de terceros». En el primer supuesto, los particulares tienen un pleno poder de disposición sobre la «relación jurídico-material», pudiendo resolver los «desajustes» ocasionados como consecuencia del conflicto, entre otras posibilidades (ej., arbitraje, transacción, no reparación del «conflicto», dejando la relación desajustada, etc.), a través del proceso. En el segundo supuesto, los particulares se ven obligados, si desean solventar el «conflicto»o, en su caso, tener reconocida, a partir de un determinado momento, una concreta situación jurídica, a acudir a los Tribunales.

De acudir al proceso, hemos de advertir que acontece, en ambos casos, algo similar: los sujetos se someten a la potestad jurisdiccional. Y acuden a los Tribunales para pedir la tutela judicial frente al desajuste de su relación, para que el sujeto o los sujetos que, en concreto, han motivado dicho desajuste (así, el comprador que no ha pagado la cosa o el padre que no ha reconocido al hijo), procedan a reparar el daño causado y a llevar a cabo las acciones (así, el pago o la devolución de la cosa, en el primer ejemplo, o el reconocimiento y, en su caso, la manutención, en el segundo) que dejaron, en su momento, de realizar, provocando con ello el «desajuste» de la relación material.

Ahora bien, la realización material de esas acciones, fruto de la relación jurídico-material anterior, requerirá, a su vez, de la previa relación jurídico-procesal, que se entablará en el proceso, dando entrada, además de a los sujetos afectados, a un tercero imparcial, el Juez, cuyo oficio consistirá en "adecuar», «ajustar», "aplicar el Derecho objetivo» al caso concreto, tratando de compensar, del modo más justo posible y sin perjuicio de la falibilidad humana, la relación jurídico-sustantiva. La decisión del Juez obligará, en su caso, al sujeto que hubiere provocado el desajuste, a llevar a cabo las «acciones» materiales que motivaron dicho desajuste. 
El presupuesto de la relación jurídico-material previa al proceso civil lo constituye, al igual que en el proceso civil, una acción, una «actio» o, en palabras de JIMÉNEZ DE ASSÚA ${ }^{56}$, una «conducta humana voluntaria que produce un resultado». Ahora bien, cuando la relación jurídico-material se encuentra descompensada y la naturaleza de dicha relación es de derecho público (en el supuesto de la comisión de una actuación delictiva) resulta preceptivo, siempre y en todo caso, acudir a los Tribunales, para que ellos ejerzan, en representación del Estado, el ius puniendi o derecho al castigo, a quién corresponde en régimen de exclusividad, quedando facultadas las partes (así, en nuestro ejemplo, la víctima) a permanecer en el proceso y, en su caso, a obtener una reparación material resarcitoria de los daños y perjuicios ocasionados. La relación jurídico-procesal que surge, en el seno del proceso penal, como consecuencia inmediata de la relación jurídico-material anterior, difiere enormemente de la obtenida en el ámbito privado. Y ello fundamentalmente debido a la circunstancia de que ningún particular, ni aún el perjudicado por el delito, tiene derecho a castigar a otro, constituyendo, sin embargo, un interés de todos los ciudadanos, el que se castiguen, por parte del Estado, las conductas contrarias a sus derechos y libertades.

Llegado el momento de acometer una reflexión sobre el concepto de «acción», partimos de una premisa lógica, que no por evidente, resulta menos esclarecedora. La «acción» o el «derecho de acción» tan sólo despierta o se «activa» procesalmente, en su posición activa, o se «resiste», en su posición pasiva, bien cuando se ha producido un conflicto intersubjetivo o social; o bien cuando, sin necesidad de esta "controversia» previa ${ }^{57}$, una determinada situación jurídica requiere o precisa una concreta tutela judicial.

El goce pacífico de los derechos, en el orden privado, y la convivencia pacífica de los ciudadanos, en el ámbito público, salvo rara excepción, no precisan tutela judicial alguna. El derecho de acción surge, en consecuencia, para tutelar situaciones en las que se producen,

56 Vid., al respecto, JIMÉNEZ DE ASÚA, L., quién advierte, además, que utiliza la palabra acto en una acepción más amplia, comprensiva del aspecto positivo acción y del negativo omisión. Así aclarado el vocablo, puede definirse el acto: manifestación de voluntad que, mediante acción, produce un cambio en el mundo exterior, o que por no hacer lo que se espera deja sin mudanza este mundo externo cuya modificación se aguarda», en "Principios de Derecho Penal. La Ley y el delito», cit., p. 210.

57 Vid., WACH, A., quien ha expuesto, de manera muy gráfica, que «el derecho que no es amenazado o que ha sido satisfecho no requiere tutela», "Manual de Derecho Procesal Civil», vol. I, Ediciones jurídicas Europa-América, Buenos Aires, 1977, p. 43. 
por parte de unos ciudadanos, amenazas a la vida, a la libertad, a la integridad o a los derechos subjetivos privados, de los demás.

El derecho de acción — que, según los autores de la Teoría concreta, es anterior e independiente del proceso- debe, en verdad, su existencia, tanto a la necesidad de «reparación» judicial de determinadas agresiones, surgidas con anterioridad al momento de su ejercicio - y que no podrían ser solventadas directamente por los particulares-, como al reconocimiento judicial de nuevas situaciones jurídicas e incluso a la defensa de derechos subjetivos concretos.

El derecho de acción es, en efecto, anterior al comienzo del proceso, toda vez que la «expectativa» de su ejercicio existe desde un momento anterior en el tiempo al surgimiento del «litigio» o "situación jurídica» precisada de tutela judicial. Asimismo, el derecho de acción puede ser calificado de «independiente» del proceso en aquellos supuestos en los que no pasa de ser una mera «expectativa», esto es, cuando los particulares solucionan, siempre y cuando, claro está, se trate de derechos disponibles, su «conflicto» sin necesidad de solicitar la apertura del proceso.

Pese a lo anterior, no podemos, sin embargo, aceptar que el derecho de acción sea independiente del proceso en aquellos supuestos en los que la declaración de un determinado derecho, la constitución de una determinada situación jurídica o la condena a la realización de una determinada prestación dependan de que así se disponga en la sentencia. Ni mucho menos, claro está, en aquellos otros supuestos en los que los Jueces y Tribunales hayan de decidir sobre el ius puniendi, que, como es sabido, corresponde, en exclusiva, al Estado, representado, en el trascendental ejercicio de «juzgar y hacer ejecutar lo juzgado», únicamente por aquellos profesionales del Derecho. Sobre el alcance temporal de la acción volveremos más adelante.

Ahora bien, el límite temporal del derecho de acción - que lo estimados conformado, en el marco del proceso que la instrumenta, desde la primera petición de tutela dirigida al órgano judicial hasta la obtención de la sentencia definitiva y firme- no nos parece tan importante como su verdadero alcance y extensión, una vez ejercitado, a través de la pretensión de una concreta tutela judicial.

En este sentido, hemos de advertir que nuestra reflexión parte de la adhesión a la concepción de la bilateralidad de la acción, y, por tanto, consideramos que el derecho de acción, en su ámbito subjetivo, tiene una doble proyección. Así, de un lado, la proyección activa, que corresponde, tanto al «actor» o «demandante», como al «ofen- 
dido o perjudicado por el delito» e incuso a un «tercero» y puede ser concebida como una facultad-posibilidad o como una carga, según se trate, en el primer caso, de un derecho a la interposición de una demanda para, a modo de ejemplo, recuperar la posesión de una «cosa» propia, o de mantener una posición activa en el proceso penal dirigido a la demostración probatoria de la «culpabilidad» del presunto autor de un hecho delictivo, así como, en el segundo caso, a la defensa de algún derecho de naturaleza social. La proyección pasiva del derecho de acción corresponde, naturalmente, al demandado o, en su caso, al imputado o acusado. Las posiciones o "roles» que ocupan en el proceso unos sujetos y otros son, como es lógico, completamente diferentes, si bien todas ellas coinciden en el ejercicio, ya sea desde una posición activa, ya desde una posición pasiva, del derecho a la tutea judicial efectiva, en la medida en que a todos ellos interesa, o al menos - salvo conductas patológicas- debiera interesar, la obtención de un resultado lo más «ajustado» posible a la Justicia.

El derecho de acción se ejercita, en este sentido, tanto por el «actor» que decide dinamizar su controvertida «situación jurídica», sometiendo al criterio del Juez o Tribunal, una concreta pretensión de tutela, como al «sujeto pasivo» de esa relación procesal, que también «pretende», «pide», «solicita», de ese mismo Juez o Tribunal, su absolución.

Una vez analizado el alcance subjetivo del derecho de acción, hemos de reconsiderar, a la vista de las Teorías estudiadas, el alcance objetivo de dicho derecho y preguntarnos si el derecho de acción ha de identificarse con el derecho a la sentencia favorable, tal y como lo conciben los partidarios de la teoría concreta o, por el contrario, con el derecho a una sentencia justa, sin más, adhiriéndonos, en tal caso, a la tesis mantenida por los autores de la teoría abstracta de la acción.

Antes de tratar de alcanzar algún resultado hemos de advertir que, aún cuando no podemos concebir la «acción» como un puro derecho subjetivo material, tampoco nos parece deseable calificarlo como un derecho subjetivo procesal en sentido estricto.

Si concibiésemos la «acción» como un «derecho subjetivo material» puro, habríamos de convenir que su existencia depende, en exclusiva, de presupuestos sustantivos, regulados en las normas de derecho material, sin la menor incidencia, en su realidad judicial, de las normas del procedimiento. Ello no es así. Los Jueces y Magistrados habrán de averiguar, incluso con carácter previo al examen de los 
presupuestos de fondo, si concurren los requisitos procesales exigibles para la composición del proceso. En el supuesto de que faltase algún presupuesto procesal -imaginemos, a modo de ejemplo, que hubiere transcurrido el plazo de caducidad o, en otro caso, que concurriese cualquier presupuesto o excepción procesal de los contenidos en el art. 416 LEC-, en modo alguno podría encauzarse el litigio por la vía judicial. Y naturalmente opinamos, como luego expondremos más ampliamente, que una persona puede tener "acción» y carecer de proceso, siendo en tal caso aquella una «acción meramente virtual», esto es, un derecho irrealizable, toda vez que su expectativa de Justicia no podrá materializarse.

La acción sólo se materializa o instrumenta, como luego veremos, a través del proceso ${ }^{58}$. Ello no significa, sin embargo, que la «acción» deba quedar reducida al proceso, puesto que esto supondría encorsetarla en una "realidad finita» susceptible de eventuales fallos o errores humanos. La realidad de la acción, hemos de anticipar, es más amplia que la del proceso.

Si concibiésemos la «acción», contrariamente a lo anterior, como un «derecho subjetivo procesal puro», entonces la existencia de la acción dependería, en exclusiva, de las normas de procedimiento, meramente instrumentales, con independencia de las normas habilitantes de naturaleza sustantiva. En este supuesto se encontrarían quiénes, pese a haber entablado una «relación procesal» perfectamente válida, se conformasen con una pretensión meramente procesal. Parecería patológica la conducta del justiciable que aspirase a obtener una resolución meramente procesal.

Si existe el «derecho procesal»es, sencillamente, porque «instrumenta» el «derecho sustantivo». El «derecho procesal», individualmente considerado, carece de virtualidad.

En este sentido, nos parece necesario advertir que el derecho de acción es un derecho subjetivo de naturaleza material cuyo éxito, en el marco del proceso, se hace depender, de un lado, de la concurrencia de los presupuestos procesales y, naturalmente, de otro, de la preexistencia de los derechos subjetivos materiales aducidos por las

58 En sentido similar al que nosotros proponemos en el texto, se ha pronunciado SATTA, S., cuando ha señalado que "la idea de acción como contrapuesta a las acciones surge justamente del proceso, o sea de la consideración de su ejercicio, porque aquí la acción, vaciada de su contenido y de su objeto inmediato, se pone en relación con el Juez, a quién se pide y de quién se espera la producción del efecto garantizado por la norma», en «Manual de Derecho Procesal civil», vol. I, Ediciones jurídicas Europa-América, Buenos Aires, 1971, p. 119. 
partes en sus respectivas pretensiones. Es por ello por lo que no podemos afirmar que el derecho de acción sea el derecho a la obtención de la sentencia favorable.

El objeto del proceso, en este sentido, no lo constituye la acción, cuya eficacia depende, insistimos, tanto de la preexistencia de derechos subjetivos materiales, como de presupuestos procesales, sino la "pretensión», que, ya sea activa —en el «derecho de acción» propiamente dicho- o pasiva - en el "derecho de defensa», que no es sino el lado pasivo del «derecho de acción»- triunfará cuando, concurriendo los presupuestos procesales, pueda, asimismo el justiciable, demostrar, de un lado, su legitimación ${ }^{59}$, y, de otro, su fundamentación acorde con la norma jurídica.

Aún cuando concurran los requisitos recién enunciados, los Jueces y Magistrados, naturalmente, pueden dictar, por dolo o negligencia, resoluciones judiciales «injustas», pero ello no desvirtúa, a nuestro juicio, la anterior afirmación.

El derecho de acción ha de aspirar, al igual que los restantes derechos fundamentales, a alcanzar la Justicia universal, es evidente, y en este sentido ha de ser conceptuado como el «derecho a la Justicia», entendiendo por «Justicia», no el mero acceso a los Tribunales de Justicia, sino a lo que en verdad «es Justo».

Estimamos que el contenido del derecho al proceso, mucho más modesto que el derecho de acción, ha de conformarse con el siguiente: es un derecho subjetivo de naturaleza procesal, instrumento imprescindible del Derecho objetivo de naturaleza sustantiva, al que debe su razón de ser, cuando ha surgido un «conflicto»o, sencillamente, cuando una determinada situación jurídica requiere la intervención judicial, que aspira a la obtención de sentencias justas, a ser posible de fondo y, en todo caso, motivadas, congruentes y estables.

Los autores de la Teoría concreta estiman, — tras afirmar que el éxito del derecho de acción depende de presupuestos jurídico-materiales, frente al derecho al proceso, que depende, en otro caso, de presupuestos procesales - finalmente que el destinatario de la acción,

59 A propósito de la «legitimación» conviene recordar, con ROSENBERG, L; SCHWAB, K. H. y GOTTWALD, P., que a diferencia de la capacidad para ser parte y de la capacidad procesal — que son cualidades personales y se determinan por circunstancias subjetivas - la legitimación —o capacidad de dirección procesal- es el derecho a dirigir un proceso como parte, ya sea en nombre propio, ya en nombre ajeno, en «Zivilprozessrecht», Verlag C.H. Beck, München, 16 auflage, 2004, p. 272. 
el sujeto pasivo de ese derecho no puede ser otro que quién está en condiciones de otorgar la tutela, que es, justamente, el Estado ${ }^{60}$.

Vamos a concluir con una serie de reflexiones a propósito del derecho de acción, que comparten, en gran medida, algunas tesis de la teoría concreta, sin por ello, despreciar buena parte de las ideas principales de la teoría abstracta. Nos parece conveniente cohonestar ambas teorías de cara a tratar de elaborar un ensayo de concepto del derecho de acción.

Partimos de una paradoja: La acción va más allá del proceso. El proceso es el instrumento de la acción. La acción abarca momentos que alcanzan períodos de tiempo anteriores, presentes y posteriores al proceso. El fundamento de la acción va más allá del proceso. La acción no puede quedar reducida al proceso. Ahora bien, la acción -y esta es la paradoja - no tiene más realidad que la que el proceso le otorga. El proceso confiere realidad a la acción. La acción sin proceso es meramente virtual.

En un ejemplo claro, el comprador que adquiere la cosa sin pagar el precio se encuentra en potencia respecto del pago y en acto respecto de la "cosa entregada» para con el vendedor, cuya relación con el primero, en el ámbito procesal, es inversa a la recién descrita.

Comprador (en potencia: debe pagar) $\Rightarrow$ Vendedor (en acto: ha entregado la cosa)

Vendedor (en potencia: tiene acción) $\Leftrightarrow$ Comprador (en acto: cuando haya sido demandado).

La relación jurídico-material inicial otorga al vendedor una acción en potencia que podrá convertir en acto, esto es, que podrá realizar o materializar a través del proceso. El derecho de acción es, evidentemente, anterior al proceso, si bien la acción, insistimos, no se puede realizar sin proceso.

Los resultados del ejercicio de la acción, una vez «actualizada», pueden ser diversos. La finalización del proceso con una resolución meramente procesal supondría, inevitablemente, la inexistencia de la adopción de una decisión sobre la «acción material» inicialmente sometida a tutela judicial.

${ }^{60}$ Vid., en este sentido, DE LA OLIVA SANTOS, «Sobre el derecho a la tutela jurisdiccional. La persona ante la Administración de Justicia: derechos básicos», cit., p. 31 . 
La finalización del proceso por algún medio anormal de finalización (renuncia, desistimiento, allanamiento, transacción, satisfacción extra-procesal) supondría, sin embargo, que la «acción sustantiva» (entrega de la cosa sin el correlativo pago de su precio) ha sido satisfecha y, en consecuencia, la "acción» en potencia (reclamación del pago o, en su caso, de la devolución de la cosa, por la vía judicial) ha pasado al acto, esto es, ha alcanzado un resultado a plena satisfacción de los sujetos implicados en el proceso.

La finalización del proceso con una sentencia de fondo sobre la tutela judicial solicitada supone, naturalmente, la realización de la acción, si bien dicha acción, con independencia de cual sea el contenido de la resolución judicial - favorable o contraria a la pretensión del actor o defensa del demandado- no se agota en dicho «decir» del Juez o Magistrado. La acción ha de ir más allá. La acción ha de comprender una realidad más amplia que la «realidad» descrita por el Juez o Magistrado. En este sentido, el proceso ha de «ajustarse» a la acción. Nunca la acción al proceso. Y ello es así puesto que la realidad de la acción aspira a la realización de la Justicia. El proceso, como instrumento de la acción, constituye una parte de su recorrido. Ahora bien, la sentencia dictada en ese proceso de la primera instancia podrá ser recurrida y también a la fase de recurso habremos de denominar acción.

Los autores de la Teoría concreta identifican el derecho de acción con el derecho a la Justicia y, en este sentido, los particulares continúan teniendo derecho de acción, con independencia de que sus pretensiones hayan sido desestimadas en el proceso, siempre y cuando sean acordes al ideal «Justicia».

Los autores de la teoría abstracta, sin embargo, parecen, en este punto, otorgar mayor valor a la economía procesal y a la seguridad jurídica, en la medida en que explican que el derecho de acción se agota en el proceso, esto es, no tiene más realidad que la del proceso.

Nosotros pensamos que ambas teorías alcanzan, parcialmente, y ninguna de ellas en su totalidad, a exponer la realidad de la acción. Concluimos este estudio con una exposición sucinta de nuestro punto de vista. La acción alcanza una realidad global, total, universal.

La acción ha de procurar ser identificada con el paso de la «potencia» (derecho al proceso) al "acto» (ejecución de la sentencia justa) de la Justicia, con independencia del momento en que se produzca dicha realización de la Justicia. En ocasiones puede realizarse al margen del proceso, así a través, a modo de ejemplo, de una recíproca resignación de voluntades que se «ajusta» muy aceptablemente a 
las pretensiones de los inicialmente actores y demandados. En ocasiones, sin embargo, necesita del proceso y a través de su realización alcanza resultados satisfactorios, así merced a la obtención de una sentencia justa. En otras, lamentablemente, la acción permanece «frustrada» una vez finalizado el proceso, habida cuenta de la obtención de una sentencia injusta sobre la que, por razón de su firmeza, ya no se puede volver. En este último caso no podemos afirmar categóricamente la inexistencia de la "acción», sino sencillamente, la del «instrumento» - el proceso- en virtud del cual aquella «acción» pudiera ser, de nuevo- materializada.

Ahora bien, si por «acción» no entendemos una realidad más amplia que la de la realización del proceso y la obtención de la sentencia, entonces careceríamos absolutamente de una mínima perspectiva de Justicia y la «acción» se limitaría, al igual que el proceso, al «decir» de los Jueces, con independencia de la Justicia o Injusticia dimanante de sus resoluciones. Nos parece ésta una realidad muy estrecha. El horizonte de la acción ha de ser más amplio.

Así las cosas, compartimos con los autores de la Teoría concreta la tesis concerniente a que la acción es anterior al proceso, pero discrepamos en que sea, sin embargo independiente del mismo, toda vez que la «acción» anterior al proceso es virtual —una acción en potencia- y la posterior, esto es, la "acción» existente tras la sentencia firme, es una acción «frustrada». Existe en la medida en la que existe el ideal Justicia y su perspectiva nos parece imprescindible: $\dot{c}$ desde dónde se puede analizar la «injusticia» dimanante de algunas resoluciones judiciales si la realidad viene compuesta, estrictamente, por el contenido de dichas resoluciones? Así, pues, la acción existe con independencia del proceso (coincidimos con la Teoría concreta) pero tan sólo se materializa a través del proceso (coincidimos con la Teoría abstracta).

Si entendemos por "acción», el derecho a la realización material de la Justicia, de lo que es Justo, de lo «más ajustado» posible a la pretensión, entonces hemos de advertir que dicho encomiable fin (la obtención de la «decisión justa») no debiera reparar o escatimar en medios y en este sentido, sería conveniente que se celebrasen tantos procesos, cuántos fueren necesarios para alcanzar aquel noble objetivo. El legislador, sin embargo, reguló, por razones de seguridad jurídica y de economía procesal, un número tasado de recursos, que, con independencia de otros múltiples factores (así, la complejidad del asunto, las razones aducidas por las partes, la escasez de conflictos de esta naturaleza, etc.), pondrán fin de una manera definitiva e irrevocable al litigio. Y ello con independencia de que se hubiere alcanzado la Justicia material o, en otro caso, quede frustrada, dicha legítima aspiración. 
Quiénes defendiesen, en este ámbito, un criterio «racional» puro, debieran impulsar la necesidad de celebrar cuántos procesos (o instrumentos) fueren precisos para alcanzar la Justicia. Los medios son escasos. Son de sobra conocidas las estadísticas del «atraso» sufrido en los juzgados como consecuencia, en buena medida, del escaso número de Jueces que hay en España, en su correlativa proporción al número de habitantes. Los particulares, asimismo, precisan una Justicia rápida, ágil y efectiva, lo que no resulta conciliable, las más de las veces, con la obtención de la decisión más Justa.

Así, pues, el derecho a la Justicia o derecho de acción ha de tener una perspectiva más amplia que la ofrecida por el derecho al proceso. Y ello debido no sólo a que el «derecho» —en el sentido de lo que es «derecho», «lo que es justo», lo que es «recto»- no se puede limitar al «decir de los Jueces», sino también porque la inexistencia, en el terreno de la Justicia, de una perspectiva más amplia que la del proceso y los recursos que, por razones fundamentalmente económicas, tengan previstos las distintas Leyes de procedimiento, podrían justificarse verdaderas atrocidades.

La existencia del derecho de acción, una vez concluidos todos los procesos que lo han instrumentado, tiene, por tanto, su razón de ser, en la necesidad de una perspectiva de lo «Justo» que puede eventualmente escapar a la realidad del proceso. Ello no significa que no pueda realizarse inmediatamente $\mathrm{y}$, en este sentido, puede afirmarse que el derecho de acción se habrá ejercitado plenamente en la primera instancia, sin necesidad de ulterior perspectiva, cuando se haya alcanzado, en este tramo procesal, la solución más ajustada a Derecho. Pero nuestra realidad no puede conformarse con los casos en los que se obtiene una rápida reparación del mal causado ajustada a Derecho, sino que ha de alcanzar también a aquellos otros que no llegan a alcanzar, después de la sentencia, una solución justa.

Si permitimos que la realidad se conforme con la solución judicial adoptada en la última instancia procesal posible, siendo esta última resolución, como pudiera perfectamente suceder, una resolución judicial injusta ${ }^{61}$, entonces estaríamos consintiendo, si se quiere pasi-

${ }^{61}$ De esta paradoja se hizo eco, en su momento, CARNELUTTI, F., cuando, tras hablarnos de la falibilidad de los Jueces afirmó: «la contradicción es esta: que el error judicial no se puede negar. Cuando una decisión ha pasado a ser irrevocable, vale como verdad. La fórmula antigua: res iudicata pro veritate habetur [ la cosa juzgada se tiene por verdad], no se atreve a declarar que la cosa juzgada sea la verdad, sino que se la considera como tal», en "Cómo se hace un proceso», Ed. Tremis, $2^{\text {a }}$ ed., Sta Fe de Bogotá, Colombia, 1994, p. 163. 
vamente, la generación de nuevos actos injustos ${ }^{62}$, lo cual, en el terreno de la política legislativa de un país democrático, podría resultar muy pernicioso.

Por tanto, en síntesis, el derecho de acción es el derecho a la Justicia, que se instrumenta, sin por ello agotarse en su seno, a través del derecho al proceso, en tanto, éste último, que derecho subjetivo de naturaleza procesal que aspira a la obtención de sentencias justas, a ser posible de fondo y, en todo caso, motivadas, congruentes y estables.

El objeto del proceso viene integrado, tal y como ya hemos avanzado, por la pretensión. La pretensión no es un derecho sino una mera "petición», efectuada ante el órgano judicial, ya sea desde el lado activo (pretensiones declarativas, constitutivas y de condena), ya desde el pasivo (pretensión de absolución) con vistas a que éste responda, por el «cauce» o "vía» del proceso, de manera motivada, congruente y estable.

Finalmente, conviene advertir que, al igual que dentro del concepto de «acción» hemos englobado la "acción» propiamente dicha y la defensa; dentro del concepto de "pretensión» hemos de incluir y, asimismo, distinguir entre la pretensión, a la que CARNELUTTI ${ }^{63}$ ha denominado «exigencia de la preponderancia de un interés propio ante un interés ajeno" y la oposición a tal exigencia.

\section{BIBLIOGRAFÍA}

ALCALÁ-ZAMORA Y CASTILLO, N., «Nuevos estudios de Derecho Procesal», Ed. Tecnos, Madrid, 1980.

${ }^{62}$ Y no olvidemos, además, que la injusticia actual genera, invariablemente, injusticia y la injusticia pasada puede, eventualmente, ser fuente, en el presente y en el futuro, de nuevas injusticias. En este sentido, GOLDSCHMIDT LANGE, W., ha tenido ocasión de advertir que «Para que una injusticia cualquiera debilite el valor de un acto de justicia es menester que la injusticia persista... La esclavitud en sentido técnico-jurídico, supuesto que no reinare actualmente en ningún lugar del mundo constituye, hoy por hoy, una injusticia pasada. Sin embargo, pudiera ocurrir que se descubriere que los descendientes de esclavos sufran aún algún defecto psicosomático observable. En este supuesto subsistiría todavía la injusticia de la esclavitud y de la omisión de remediarla, por ejemplo, mediante una indemnización», en «La ciencia de la Justicia (Dikelogia)», Ed. Aguilar, Madrid, 1958, p. 64.

${ }^{63}$ Vid., CARNELUTTI, F., quién, asimismo, ha señalado que «el conflicto actual supone un acto realizado por cada uno de los sujetos, los cuales, al realizarlo, se convierten en dos contendientes, de los que uno pretende y el otro se opone a la pretensión», en "Teoría General del Derecho. Metodología del Derecho», Ed. Comares, Granada, 2003, p. 61. 
ARELlANO, C., «Teoría general del proceso», Ed. Porrua, México D.F., 1980, p. 257.

CARNELUTTI, F., «Cómo se hace un proceso», Ed. Tremis, 2. ${ }^{\text {a ed., }}$ Sta Fe de Bogotá, Colombia, 1994.

CHIOVENDA, G., «Principi di Diritto Processuale Civile. Le azioni. Il processo di cognizione», Ed. E. Jovene, Napoli, 1980.

DE LA OLIVA SANTOS, A., "Sobre el derecho a la tutela jurisdiccional. La persona ante la Administración de Justicia: derechos básicos», Ed. Bosch, Madrid, 1980.

- «Derecho Procesal. Introducción», Ed. Ceura, 2. ${ }^{a}$ ed., Madrid, 2002.

FAIREN GUILLÉN, V., «Temas del ordenamiento procesal», Tomo I, Historia. Teoría General, Ed. Tecnos, Madrid, 1969.

- «De nuevo sobre los conceptos de acción y de pretensión», Revista de Derecho Procesal n. ${ }^{\circ} 1,1988$.

FENECH, M., «Derecho Procesal Civil. Introducción. Procedimientos ordinarios de declaración y de ejecución», Ed. Agesa, Madrid, 1983.

GIMENO SENDRA, V., «Fundamentos del Derecho Procesal (Jurisdicción, acción y proceso)», Ed. Civitas, Madrid, 1981.

- «Derecho procesal civil», Tomo I, Ed. Colex, Madrid, 2008.

— «Proceso Civil Práctico», Ed. La Ley, Madrid, 2009.

GOLDSCHMIDT LANGE, W., «La ciencia de la Justicia (Dikelogia)», Ed. Aguilar, Madrid, 1958.

GÓMEZ COLOMER, J. L., «Reflexiones sobre las bases científicas de la parte general del Derecho Jurisdiccional», en «Estudios de Derecho procesal en honor de Víctor FAIRÉN Guillén», Ed. Tirant lo blanch, Valencia, 1990.

GÓMEZ ORBANEJA, E., «Derecho procesal civil», volumen primero, «Parte general. El proceso declarativo ordinario», 7. ${ }^{\mathrm{a}}$ ed., Madrid, 1975.

GUASP, J., «Derecho Procesal Civil», Tomo I, Introducción y parte general, Instituto de estudios políticos, Madrid, 1968.

GUIMARÀES RIBEIRO, D., «La pretensión procesal y la tutela judicial efectiva», Ed. Bosch, Barcelona, 2004. 
JIMÉNEZ DE ASÚA, L., «Principios de Derecho Penal. La Ley y el delito», Ed. Abeledo-Perrot, 3. ${ }^{\mathrm{a}}$ ed., Buenos Aires, 1958.

MONTERO AROCA, J., «Derecho Jurisdiccional», Parte General, Ed. Tirant lo blanch, Valencia, 2003.

MONTESANO, L., «La tutela giurisdizionale dei diritti», Tomo $4 .^{\circ}$ del «Trattato di Diritto Civile italiano», Ed. Utet, Torino, 1985.

PRIETO-CASTRO Y FERRÁNDIZ, L., «Tribunales españoles. Organización y funcionamiento», Ed. Tecnos, Madrid, 1973.

— «El derecho a la tutela jurisdiccional», en «Jornadas de Derecho procesal», Consejo General del Poder Judicial, Madrid, 1984.

ROSENBERG, L; SCHWAB, K. H. y GOTTWALD, P., «Zivilprozessrecht», Verlag C. H. Beck, München, 16 auflage, 2004.

SATTA, S., «Manual de Derecho Procesal civil», vol. I, Ediciones jurídicas Europa-América, Buenos Aires, 1971.

WACH, A., «Manual de Derecho Procesal Civil», vol. I, Ediciones jurídicas Europa-América, Buenos Aires, 1977. 
